\title{
Investigating the Thermal and Mechanical Performance of Polylactic Acid (PLA) Reinforced with cellulose, wood fibers and Copolymer
}

\author{
*Hassan K. Langat ${ }^{1}$, Kiril Dimitrov ${ }^{2}$, Michael Herzog ${ }^{2}$, Peter Muchiri ${ }^{1}$, \\ James Keraita $^{1}$ \\ ${ }^{1}$ (Department of Mechanical Engineering - Dedan Kimathi University of Technology, 657-10100, Kenya) \\ ${ }^{2}$ (Faculty of Engineering and Natural Sciences- Technical University of Applied Sciences - Wildau 15745, \\ Germany) \\ Corresponding Author: Hassan K. Langat
}

\begin{abstract}
Polylactic Acid, a sugar based biodegradable polymer possesses attractive properties that makes it a candidate for sustainable applications. However, other properties limiting an application like low thermal stability, reduced mechanical performance and moisture sensitivity compared to polypropylene, polyethylene and polystyrene. In the current study, properties of PLA were improved by compounding and hot pressing it with different natural commercial and readily available fibers of Kraft cellulose, wood fiber, viscouse Lyocell ${ }^{\circledR}$ and Cordenka ${ }^{\circledR}$ in mass proportions of 10\%, $20 \%$ and 30\% relative to the matrix PLA with 10\% of an additional copolymer. Charpy impact strength, tensile strength, thermal properties and morphology were investigated and compared for all composites and their possible applications. It was found that Charpy impact strength reduced with increase in fiber content with highest impact of $(63 \mathrm{~kJ} / \mathrm{m} 2)$ at $10 \%$ viscouse fiber loading. A high tensile strength of $67 \mathrm{MPa}$ was obtained from 30\% Lyocell fiber in the composite which was $4 \mathrm{MPa}$ and $10 \mathrm{MPa}$ higher than that of Kraft cellulose at the $30 \%$ fiber loading and pure PLA respectively. Modulus of elasticity reached a maximum value of $6 \mathrm{GPa}$ at 30 \% loading of Kraft cellulose. Addition of copolymer showed reduced stiffness for all the composites due to impregnation of the active sites instead of bonding hence did not improve the fiber-matrix interaction. Detailed analysis showed better fiber-matrix interface, fiber pullout and the active role played by fibers in absorbing energy thus enhancing the mechanical properties. Water absorption on the other hand showed prolonged water uptake. Thermal analysis for composite without copolymer revealed a stable crystal structure whereas those with copolymer showed different melting peaks indicative of the presence of different phases in the structure. The results obtained shows that the properties of PLA can be enhanced by addition of natural fibers in cellulosic form. This will reduce the cost of these composites and will open up an avenue in which biodegradable composites can be utilized in applications to replace the components made from non-degradable polymers.
\end{abstract}

Keywords: Polylactic Acid, cellulose, composites.

\section{Introduction}

Composites have been in use in a wide range of application mainly industrial, biomedical and light weight industries as aerospace, automotive and emerging consumer and construction industries among others [1]. This has been attributed to high strength to weight ratio among other features as flexibility in manufacturing and good corrosion resistance [2]. A composite is made by combining two or more materials with different properties to achieve materials with enhanced properties than those of the individual components used alone [3].

Bezhad D et al. [4] in their research on polymeric materials indicated that most of the commercial composites in use today for electronics are from synthetic materials. It has been estimated that the demand in the electrical and electronic segment in Europe is about 3 million tons annually and predicted to be increasing in the subsequent years specifically for consumer electronics like smartphones, tablets and pods due to their short lifespan of about 3-4 years. Proportional to the production, e-waste is expected to increase, coupled with the limited petrochemical resources used for plastic production [5].

Environmental issues associated with the disposal of these materials, cost and diminishing fossil fuels together with the new regulations has forced the industries to adopt the use of ecofriendly materials and to develop modern polymeric materials. Biodegradable polymers have been classified based on their origin namely; petroleum based and natural resource based [6]. Polylactic acid (PLA) is a natural resource based polymer and is considered a renewable resource. Recently, the applications of PLA have been extended into 
food packaging, 3D printing and medical applications. However, their applications in electronics industry has been limited by the requirements originating from manufacturing process and lifecycle of the product. The property limitations include low thermal stability, reduced mechanical performance and high moisture sensitivity compared to polypropylene, polyethylene and polystyrene [7]. Novel approaches have been investigated to enhance the limiting properties of PLA for high performance applications. Blending of PLA with other polymers have been reported by a number of researchers [8-13]. These research groups focused on miscibility, thermal behavior, mechanical properties, interfacial compatibility of different blends and the effects on crystallization of PLA. Mahanwar et al [14] studied on the network formation in microcrystalline cellulose and PLA with similar investigations as previous researchers [8-13]. A number of groups concluded that there was a possibility of blending different polymers with PLA to yield enhanced thermal and mechanical properties, however, some studies reported negative results on miscibility for polymer blends [11] and matrix adhesion [14] for cellulose-PLA interaction. These two properties have direct effect on the performance and properties of the composite. Kovacs et al [15] in their study on functional biodegradable composites for circuit boards and electronic casings, highlighted the need for further mechanical tests, reliability and reinforcement possibilities for high performance electronics applications. In spite of good properties offered by the different polymer blends and matrix reinforcement, optimum properties have not been achieved for biodegradable composites for high performance applications such as electronics industry. This research therefore, in addition to the efforts on applicability of biodegradable composites is focused on reinforcing PLA with different renewable fibers. The application of a copolymer i.e. reacting $\mathrm{OH}$-groups at the surface and/or terminal lactic acid influence the matrix-fiber interaction acting on adhesion or small deformations and friction i.e. fiber pull out in case of mechanical load. So the blend is aimed enhancing properties that can even be utilized in high performance applications.

- Materials and sample preparations.

\section{Experimental section}

Polylactic acid (PLA) was delivered from Nature Works B.V. with the trade name NatureWorks ${ }^{\circledR}$ Biopolymer 2003D with the following properties; residual monomer of $0.27 \%$, and Yellowness index of 33.3. Fibers used include bleached sulfate Kraft cellulose obtained from Svilocell EAD® Bulgaria. It is derived from hardwood local tree species as beech, poplar, cerris oak and acacia. The properties include; breaking length of $1900 \mathrm{~m}$, acc. ISO 1924/2, Tensile index of $18 \mathrm{Nm} / \mathrm{g}$ acc. ISO 1924-2, Burst index of $0.75 \mathrm{kPa} \mathrm{m} 2 / \mathrm{g}$ acc. ISO 2758 , tear index of $2.3 \mathrm{mN} . \mathrm{m} 2 / \mathrm{g}$ acc. EN 21974 and $80 \%$ brightness acc. ISO 3088 and fiber length of between 1 and $3 \mathrm{~mm}$. Regenerated cellulose of viscose type was obtained from Fraunhofer Institute for Applied Polymer Research/Germany. The fiber length was between 3.5 and $4.5 \mathrm{~mm}$. Wood fiber was sourced from regular production of Velde Bulgaria - Troyan. It is obtained by thermo-mechanical refining of hardwood in the form of technological chips, with degree of grinding - 22 DS and fiber concentration of $3.75 \%$. and fiber length of between 3 and $6 \mathrm{~mm}$. Lyocell is a form of rayon which consists of cellulose fiber made from dissolving pulp (bleached wood pulp) using dry jet-wet spinning. Lyocell type of regenerated cellulose fiber was delivered from Fraunhofer Institute for Applied Polymer Research/Germany. Lyocell shares many properties with other cellulosic fibres such as cotton, linen, ramie and viscose rayon. Some main characteristics of Lyocell fibers are that they are soft, absorbent, very strong when wet or dry, and resistant to wrinkles. Fiber length was 2 to $3 \mathrm{~mm}$. Desmodur 3475 BA/BS, delivered from Covestro, Germany, was used as a copolymer. It is a diethyl malonate type blocked, aliphatic polyisocyanate based on HDI/IPDI with blocked NCO content of approximately $8.2 \%$, viscosity of approximately $850 \mathrm{mPas}$ at $25^{\circ} \mathrm{C}$ according to DIN EN ISO 3219/A3 and density of approximately $1.1 \mathrm{~g} / \mathrm{ml}$ at $20^{\circ} \mathrm{C}$ according to DIN EN ISO 2811. Blocked polyisocyanates are another approach that requires heat for activation. Desmodur $3475 \mathrm{BA} / \mathrm{BS}$ is a polyisocyanate product that is stable at room temperature but dissociates to regenerate isocyanate functionality when heated to $1600 \mathrm{C}$. The isocyanates group, easily react with both hydroxyl and carboxyl group. Cause of this the using of Desmodur 3475 BA/BS is very appropriate as a crosslinking agent for PLA and natural fiber. The principal proposed reaction of PLA and cellulose with isocyanate is schematically presented in Fig. 1.

$$
\mathrm{R}-\mathrm{NCO}+\mathrm{R}^{\prime}-\mathrm{COOH}(\mathrm{PLA}) \longrightarrow \mathrm{R}-\mathrm{NH}-\mathrm{CO}-\mathrm{R}^{\prime} \text { (amide) }+\mathrm{CO}_{2}
$$

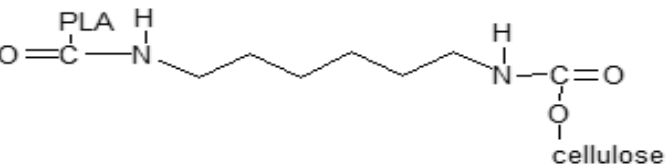

Figure 1 Principal schematically proposed chemical reaction among poly (lactid acid) (PLA), cellulose and hexamethylene diisocyanate 
The used catalyst was 1,1,3,3-Tetramethylguanidine (TMG) and was delivered from Performance Chemicals Handels GmbH, Germany. The 1,1,3,3-Tetramethylguanidine is employed as a polyurethane foam catalyst and as an accelerator for the syntheses of polysulfured rubber. The properties include, Flash point of 60 ${ }^{\circ} \mathrm{C}$, Boiling point $-162{ }^{\circ} \mathrm{C}$ and Density $-0,917 \mathrm{~g} / \mathrm{m} 3$. It was used together with the copolymer to accelerate the crosslinking process. Formulation for each composite consisted of a varying weights of fiber and PLA and constant percentage weight of copolymer to add to a machine of $300 \mathrm{~g}$ compounding capacity. Formulation ratios of $10 \%, 20 \%$ and $30 \% \mathrm{wt} / \mathrm{wt}$ fiber in $90 \%, 80 \%$ and $70 \% \mathrm{wt} / \mathrm{wt}$ matrix without copolymer and $80 \%, 70 \%$ and $60 \% \mathrm{wt} / \mathrm{wt}$ matrix with copolymer respectively were used for wood fiber, Kraft cellulose, Viscose and Lyocell regenerated cellulose. Prior to compounding, PLA was oven dried at $1050 \mathrm{C}$ for 24 hours while cellulose fiber additives at $105^{\circ} \mathrm{C}$ for 3 hours. PLA and fibers were compounded at given ratios using Brabender Plasti-Corder® lab station with 350E mixer (Germany) with three heating zones kept at $1600 \mathrm{C}$ and then hot pressed at $165{ }^{\circ} \mathrm{C}$ with a pressure of $312.5 \mathrm{~N} / \mathrm{cm} 2$ in a laboratory press Servitec/ Polystat $300 \mathrm{~S}$ (Germany) into $100 \mathrm{~mm}$ x $100 \mathrm{~mm}$ x $3 \mathrm{~mm}$ thick mold. Samples for various tests were cut to standard size as per the test.

\section{- Characterization techniques}

1. Morphology

Two different models of scanning electron microscope (FEI-Quanta 400F, Germany and JEOL JSM6010, Germany) were used to analyze and collect microscopy images of the composite specimen. The morphology of cross-section of fractured samples from tensile test was observed using SEM at room temperature in order to study the effects of copolymer and the interface between the matrix and fibers. The samples for microscopy were prepared by sputter coating with $50 \mathrm{~nm}$ thick gold layer at pressure, Pressure $\mathrm{p}$ of 10-2 bar and a current, I of 50mA. The machine used during this process was high vacuum sputter coater (LEICA EM SCD 500, Germany). The fiber surface morphology was investigated using Field Ion Microscope model Micron 9100, Germany.

\section{Mechanical Properties}

Tensile strength testing and elongation at break and impact testing for all of the specimens were carried out on a tensile tester model Zwick Z 020 (Zwick GmbH \& Co. KG, Ulm, Germany) at speed of $50 \mathrm{~mm} / \mathrm{min}$ and impact tester (PSW 4J) according to DIN EN ISO 179 standard using 10 unnotched samples respectively at room temperature. All measurements had an average of five runs. The specimen was prepared according to EN ISO 527-3:1995.

\section{Water absorption properties}

Water absorption of composites was used to determine the amount of water absorbed under specified conditions according DIN ISO 62. The measurement was done using samples with $30 \mathrm{~mm}$ length, $10 \mathrm{~mm}$ wide and $2.4 \mathrm{~mm}$ to $2.9 \mathrm{~mm}$ thickness. The samples were immersed in a glass of distilled water for 24,48 and 72 hours at $\approx 25^{\circ} \mathrm{C}$. Water absorption was expressed as increase in weight percent for each sample.

\section{Thermal analysis}

Differential scanning calorimetry (DSC) of the composite was performed on a differential scanning calorimeter DSC 204 Phoenix, Netzsch, Germany according to ISO 11357. The heating range was programmed from $-1000 \mathrm{C}$ to $3000 \mathrm{C}$ with a heating rate of $100 \mathrm{C} / \mathrm{min}$ under nitrogen atmosphere. The measurements were performed with 6-10 mg samples. DSC curves were recorded for melt temperature, glass transition temperature and crystallization structure of composite.

\section{Morphology}

\section{Results and Discussions}

Images of a cross-sectional view of tensile test samples were taken using SEM and represented as shown in the figures below. Fig. 2 shows SEM images of pure PLA and PLA with copolymer. From the images, it can be seen that there was difference in their failure mode. PLA depicts a brittle structure whereas the presence of copolymers in PLA show ductile structure.
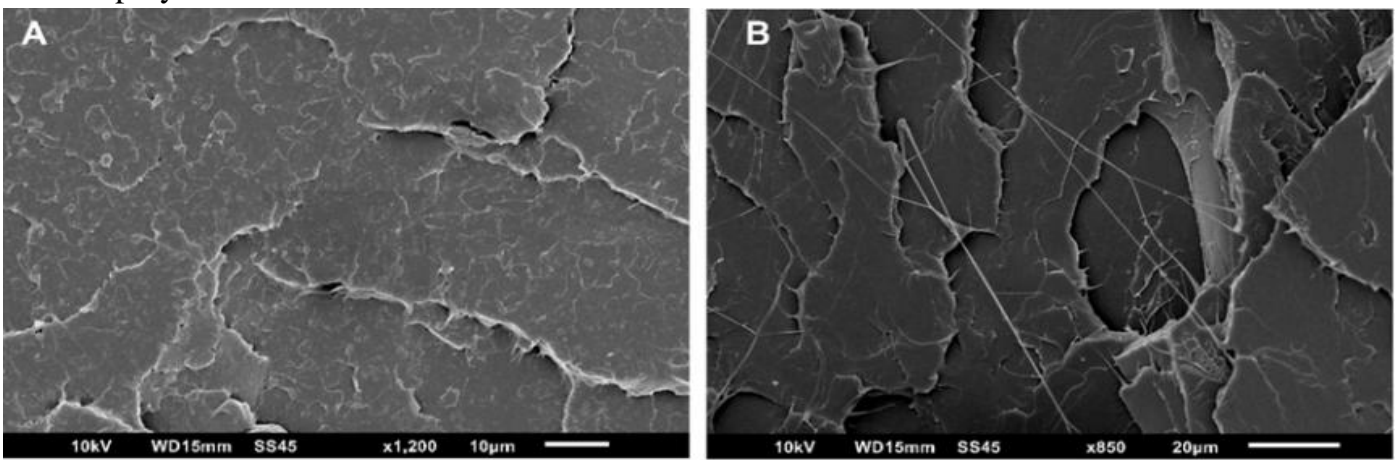

Figure. 2 (A) PLA, (B) PLA + copolymer 
It can be concluded that copolymer modified the structures of PLA from brittle to soft and ductile. Copolymer had no effect on tensile properties but had positive effect of approximately $20 \%$ increase on the impact strength.
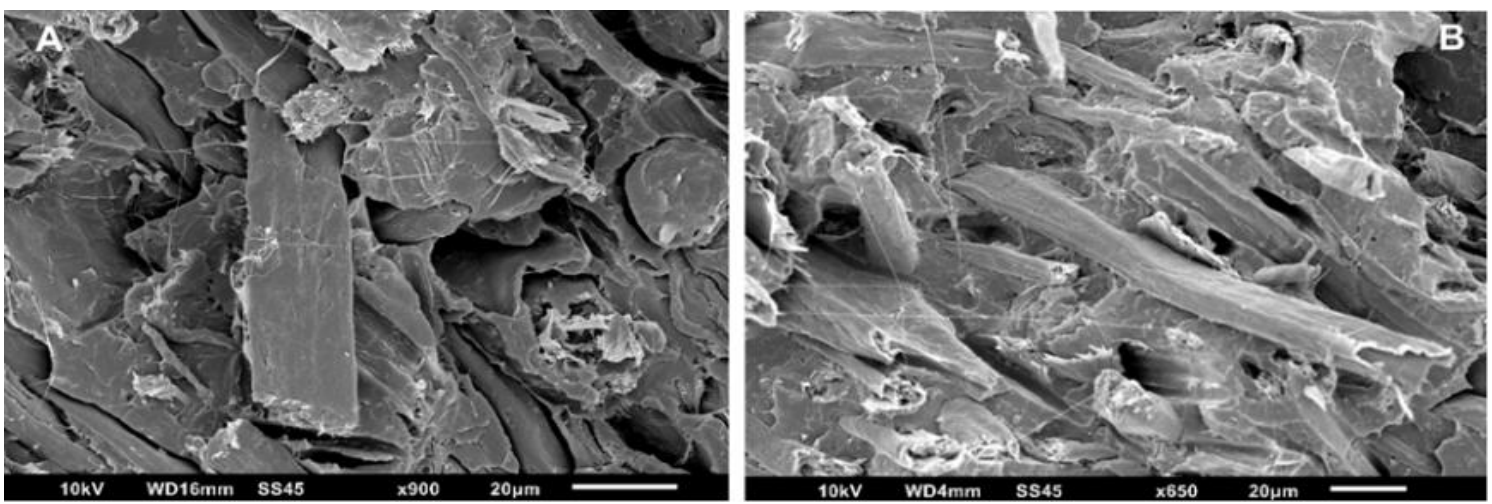

Figure 3. (A) Kraft +PLA, (B) Kraft + PLA+ copolymer

Observations derived from the images in Fig. 3 is the interface between the fiber and matrix. A shows poor interface compared to $\mathrm{B}$, indicating the effect of copolymer in enhancing the interface however, the presence of this copolymer had no effect on the mechanical properties. Uniform distribution of fibers in the matrix was also noted.
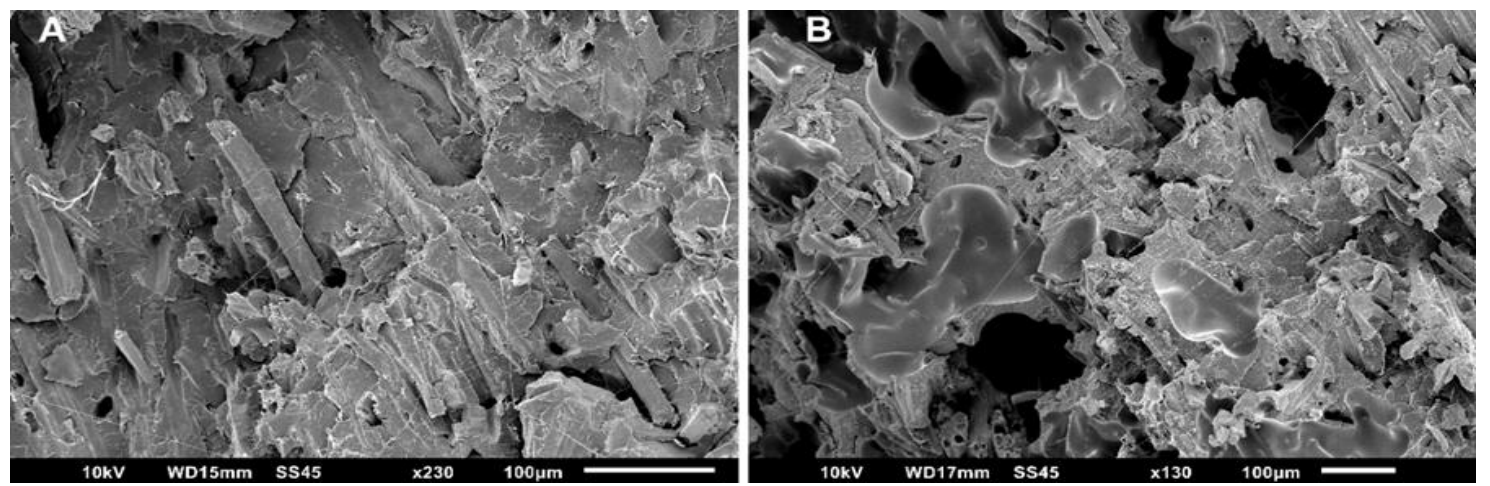

Figure 4. (A) Wood fiber + PLA, (B) Wood Fiber + PLA + Copolymer

Poor matrix - fiber interface and presence of voids were observed for composite from wood fiber though there was uniform distribution of fibers in the matrix as depicted in Fig. 4. This can be attributed to the dissociation of lignin and hemicellulose which was present in the wood fiber. The voids and non-uniform dispersion of the fibers in the matrix led to the poor mechanical performance of the composite both with and without copolymer.
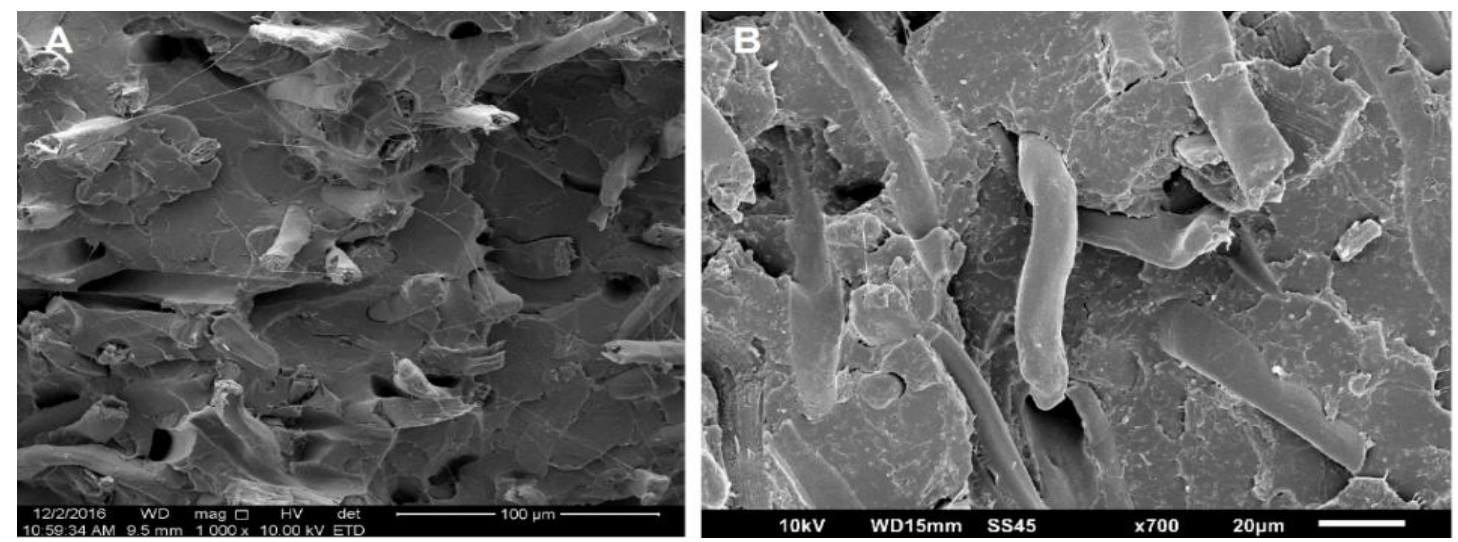

Figure 5. (A) PLA + Lyocell, (B) PLA + Lyocell + copolymer

On the other hand, good interface and homogeneous distribution of fibers in the matrix was observed for Lyocell composite as shown in Fig. 5. The fiber breakage depicts the resistance to fiber pullout and failure in tension. This resulted in good mechanical properties as discussed later. 

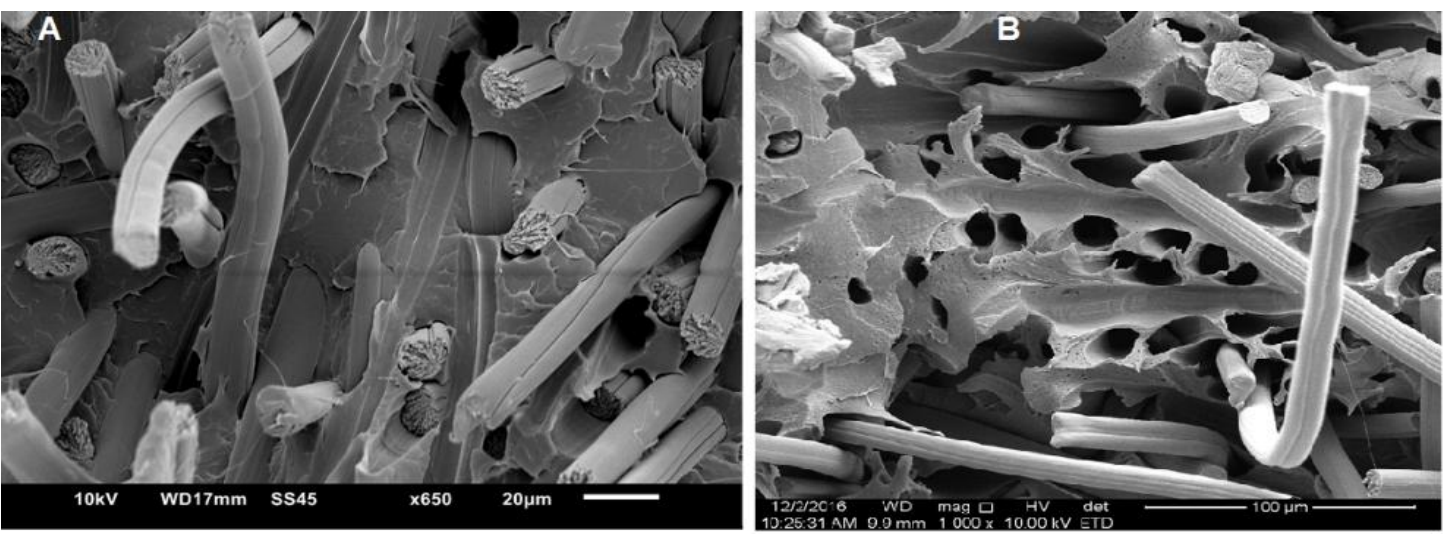

Figure 6. (A) PLA + Viscous, (B) PLA + Viscous + copolymer

Viscous cellulose had longer fibers compared to the fibers in this study. The good interface and uniform fiber integration in the matrix was clearly shown Fig. 6. Fiber pullout as shown in Fig.6 (B) indicates the ductility nature of the composite. It also shows the role of fibers in resistance to failure in tension.

\section{Mechanical properties}

\subsection{Charpy impact test}

Impact test according to DIN ISO 179 was carried out to determine amount of energy absorbed by the bio composites made from different fibers at different proportions at fracture. The data obtained were represented as shown in Fig.7 below. As expected, the incorporation of the fibres into the matrices increased their mechanical stiffness.
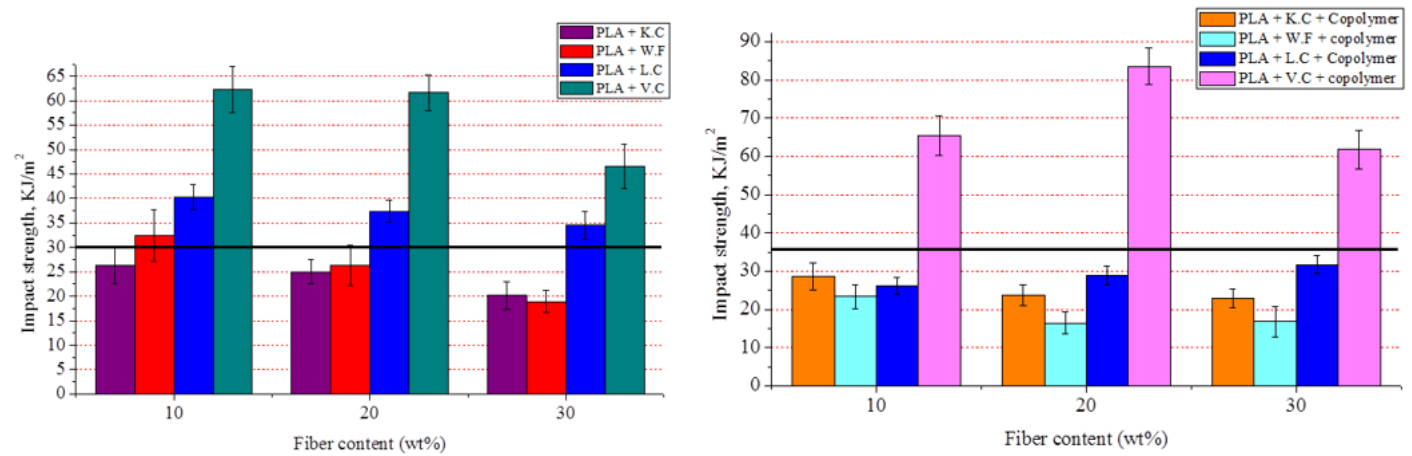

Figure 7. Impact strength graphs of the composite

Results from the test indicate that the amount of energy absorbed reduces with the increase in fiber content, with the highest at $10 \%$ for all the fibers (Kraft cellulose, wood fiber, Lyocell cellulose and viscous cellulose). This could have been attributed to weak interaction between matrix and fibers as the fiber content increases, more voids are created lowering the resistance to failure. Viscous cellulose had the highest impact strength $(63 \mathrm{~kJ} / \mathrm{m} 2)$ at a fibre-mass-ratio of $10 \%$ which is approximately 2 times higher than the value for pure PLA. The use of Lyocell can also improve the impact properties of PLA. The improvement of impact strength for the PLA composites should be attributed to the fact that fibers have different length. This variation could be as a result of different fiber size and surfaces. Wood fiber had the least impact strength at $30 \%$ fiber, physical analysis of fractured component indicates that wood fiber had poor miscibility with the matrix resulting in voids inside the composite. This could have been as a result of the presence of amorphous structure i.e. lignin and hemicellulose in the fiber. De-bonding, pull-out and fracture of the fibres are the three mechanisms of energy absorption during impact. It was assumed that the strain energy which is released by fibre de-bonding and fracture was proportional to the de-bonded length and so a poor adhesion between matrix and fibres leads to higher energy absorption as similarly reported by [16]. Addition of $10 \%$ copolymer for all samples changed the impact strength for each composite at different proportions. The impact strength for composite with Kraft cellulose decreases with increase in fiber content, similar trend was observed for wood fiber, however, for Lyocell cellulose, there was marked increase in the impact strength with increasing fiber content. Highest tendency for absorbed energy $(82 \mathrm{~kJ} / \mathrm{m} 2)$ was shown in $20 \%$ viscous cellulose content, higher than that without copolymer. 


\subsection{Modulus of elasticity}

The Young's modulus of the composite materials increases with an increase in fiber content, reaching a maximum value at $30 \%$ fiber. The Young's modulus was approximately two times higher at $30 \%$ fiber (for all composites) loading than at $0 \%$ fiber content, i.e. pure PLA as depicted in figure I. The trends of all the curves, figure VI and VII were more or less the same. The values of the Young's modulus increased progressively with increasing fiber loading. However, the largest increase with increasing fiber content was for Kraft cellulose reinforced composites, while the least increase was for the wood fibers with copolymer reinforced composites.

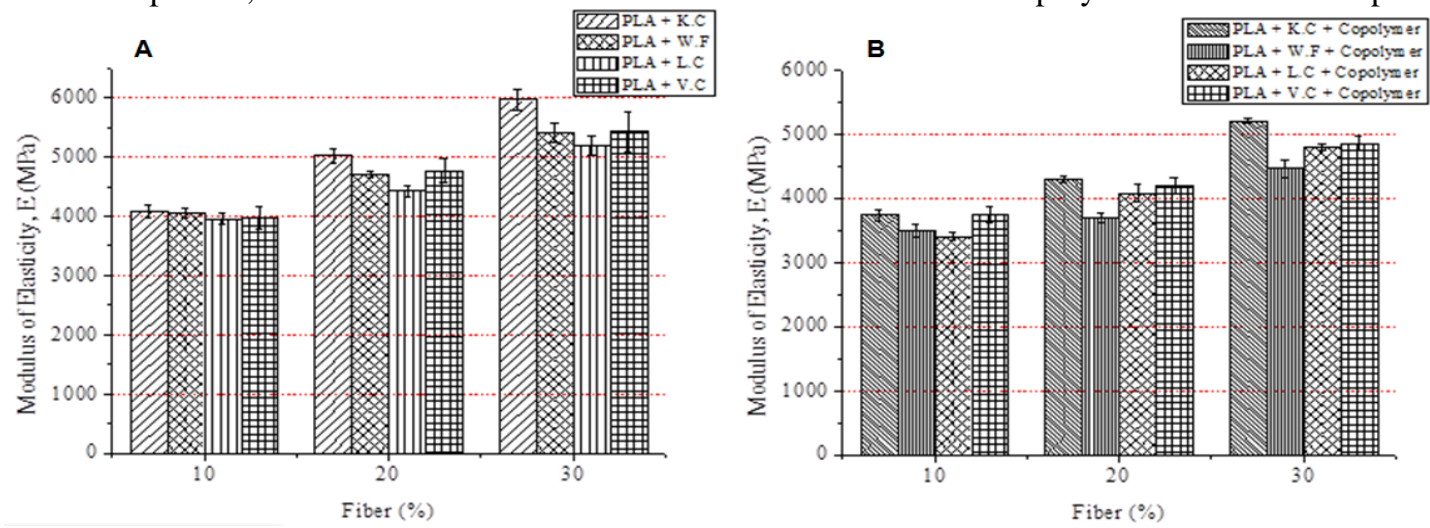

Figure 8. (A) modulus of elasticity PLA + fibre composites, (B) modulus of elasticity PLA + fibre + copolymer composites

The Young's modulus of the composite materials increases with an increase in fiber content, reaching a maximum value at $30 \%$ fibre Fig. 8 (A). The Young's modulus was approximately two times higher at $30 \%$ fiber (for all composites) loading than at $0 \%$ fiber content, i.e. pure PLA as depicted in Fig. 8 (A). The trends of all the curves, Fig. 8 (A) and (B) were more or less the same. The values of the Young's modulus increased progressively with increasing fiber loading. However, the largest increase with increasing fiber content was for Kraft cellulose reinforced composites, while the least increase was for the wood fibers with copolymer reinforced composites.

\subsection{Water absorption}

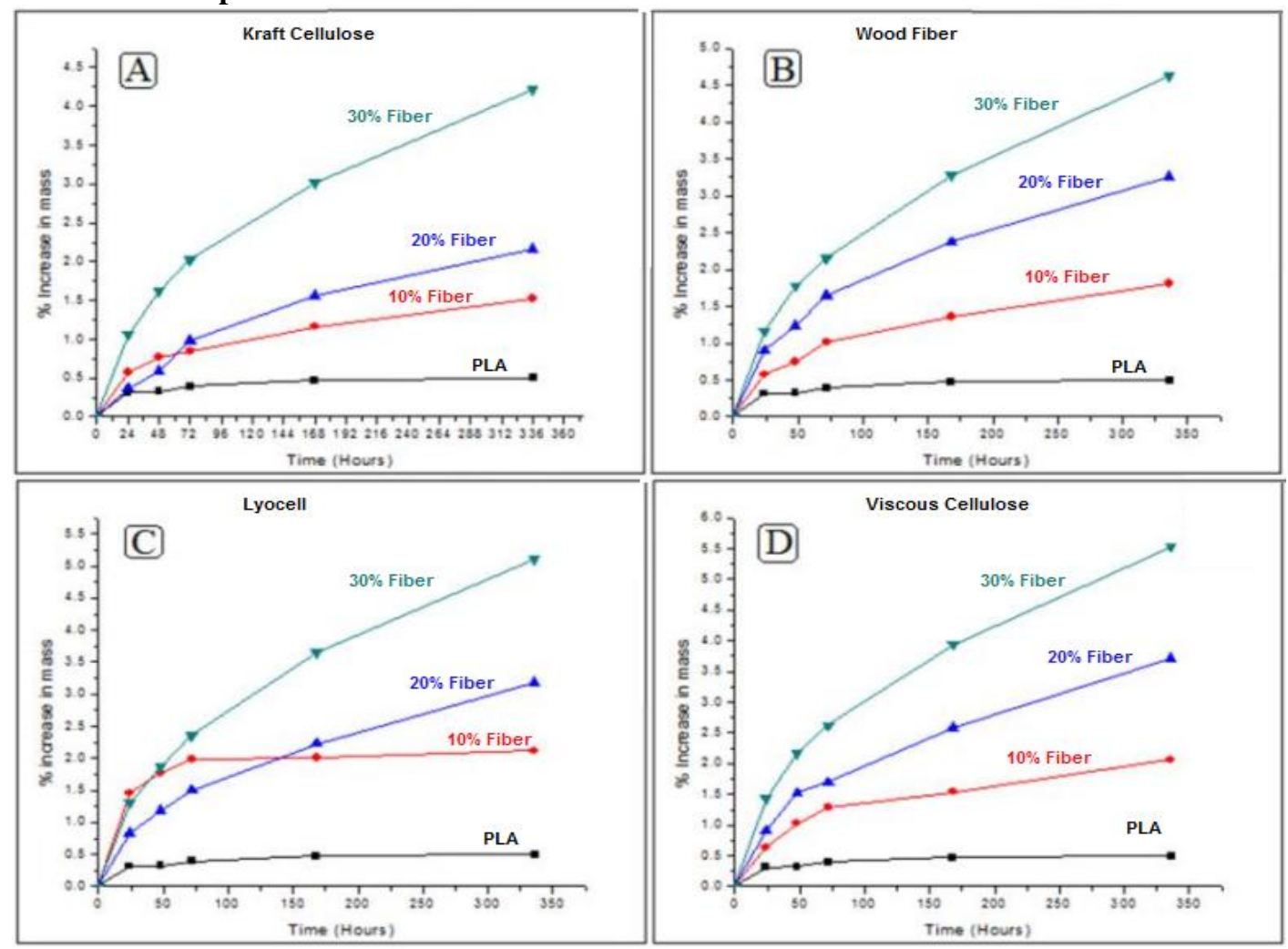

Figure 9. Water absorption curves 
The result obtained without copolymer Fig. 9 (A) showed that the water absorption increases with increase in fiber loading. This has been attributed to high porosity in high fiber content which occurs when geometrical compaction limit has been exceeded. The composites however exhibited low water uptake with approximately $2.5 \%$ maximum increase in mass for $30 \%$ fiber loading after 72 hours. $10 \%$ fiber loading for Lyocell cellulose had a rapid water uptake for the first 24 hours, which contradicts the fact that fiber loading increases the water uptake due to increase in hydrophilic groups. The increase in water absorption is due to the hydrophilic nature of natural fibre and the interfacial properties between the fibre and the matrix. At the first 24 hours, rate of water absorption was high and reduces gradually with time. All composites depicted an increase in water absorption as the fibre loading increases. After one and two weeks there was still some change in mass and the dimensions. This was attributed to micro cracking in structure allowing in more water to be absorbed thus swelling.

When natural fibre-reinforced PLA composites are exposed to moisture, the hydrophilic nature of fibre, in this case kraft cellulose, wood fibre, Lyocell and viscous cellulose, causes the fibre to absorb water and swell. As a result, micro-cracking of the PLA composite occurs. The high cellulose content in the fibre absorbs extra water that penetrates the interface through these micro-cracks, creating swelling stresses that lead to composite failure. The more the composite cracks, the more capillarity and transport via micro-cracks become active. The capillary mechanism involves the flow of water molecules along fibre-matrix interfaces and diffusion through the bulk matrix. Water molecules actively attack the interface, resulting in de-bonding of the fibre and the matrix.

\subsection{Thermal analysis}

During heating the $\mathrm{Tg}$ is shown clearly Fig. 10 along with an enthalpy relaxation peak at $59{ }^{\circ} \mathrm{C}$. As the temperature continue to rise, a endotherm peak is seen, representing a melting point of $157^{\circ} \mathrm{C}$. The pure PLA is a semi crystalline polymer and from the graph it can be seen to be having a small crystallization from the crystalline domains of PLA.

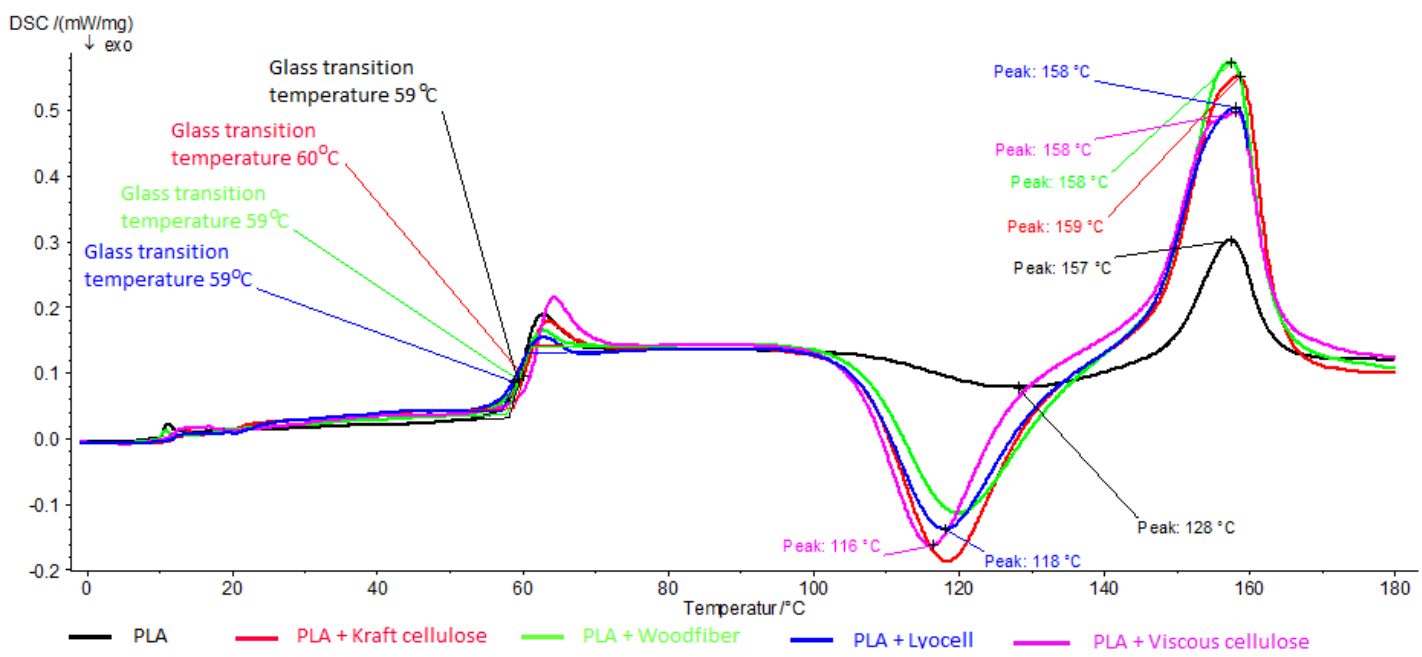

Figure11. DSC curve

All composites showed clear $\mathrm{Tg}$ at $59^{\circ} \mathrm{C}$. Crystallization can be seen as an exothermic peak starting at approximately $100{ }^{\circ} \mathrm{C}$, with maximum peak between $116{ }^{\circ} \mathrm{C}$ and $118{ }^{\circ} \mathrm{C}$. The best crystallization curve was obtained from composites with Kraft cellulose as additive. This means this composites had a stable crystal structure. Semi crystalline polymers contain both amorphous and crystalline domains and the DSC analysis of PLA composites exhibited both the glass transition temperature.

\section{Conclusions}

Addition of copolymer modified the structure of PLA from brittle nature to ductile. This was observed during the analysis of the fractured surface of pure PLA and that of PLA modified with copolymer. The terminal hydroxyl groups present in PLA structure reacted with the $\mathrm{N}-\mathrm{C}-\mathrm{O}$ presence in the polyisocyanate to form a cross linked structure thus reducing the brittleness of the PLA. The tensile strength performance was better for nonmodified compared to that of modified. The tensile moduli and strength of all the biodegradable PLA/Lyocell composites increased with increasing fiber content. The composite made of PLA reinforced with Lyocell and Viscous cellulose shows promising mechanical properties, especially the impact properties of PLA/Viscous cellulose without copolymer $(63 \mathrm{~kJ} / \mathrm{m} 2)$ and with copolymer $(82 \mathrm{~kJ} / \mathrm{m} 2)$. Other fibers show increase in strength 
and moduli with increased fiber loading without copolymer. DSC results show presence of different phase structure in each composite which could have resulted in variation of mechanical properties. During mixing, temperature and torque were the two key parameters observed, the cross liking process as theoretically assumed, was invisible, hence this chemical reaction could occur at any point in mixing. The network structure would be destroyed during hot pressing where the temperatures were kept slightly higher than the melting temperature of matrix. However, the glass transition temperature was kept at $59^{\circ} \mathrm{C}$ with different relaxation peaks. The crystallization temperature was low compared to that of pure PLA, implying that these composites has a stable crystal structure. There was a slight increase in the melting temperature in comparison to that of pure PLA. Hence stable at temperatures below $160^{\circ} \mathrm{C}$. Addition of copolymer further reduced the crystallization temperature to below $100^{\circ} \mathrm{C}$.

Water absorption increases with the fiber loading for all the composites. Fibers are hydrophilic in nature hence absorb water into their structure when exposed to the moisture. The rate of water absorption was however not intense due to the presence of matrix which block the surface of the fibers from drawing in water. However, as water is absorbed into the structure, the fiber swells, resulting in micro cracks. These micro cracks create room for more water and transfer stress to the interface between itself and matrix thus weakening it. This means more water is absorbed into the composite structure but the rate is reduced as it will be saturated. SEM micrographs shows that there was homogeneous mixing for all composites, however the interaction between the matrix and fiber was not the same for all. Lyocell had good interfacial interaction with the matrix without copolymer. Fiber pullout breakage was also witnessed which shows the active role of fibers in stress absorption.

\section{Acknowledgment}

This research was supported by DAAD-project BridG-iT! We acknowledge the receipt of the fibers from UCTM Sofia and Fraunhofer IAP.

\section{References}

[1] G. Gupta, A. Kumar, R. Tyagi and S. Kumar, "Application and Future of Composite:Overview," International Journal of Innovative Research in Science Engineering and Technology, vol. 5, no. 5, pp. 6907-6911, 2016.

[2] D. Verma, P. Gope, M. Maheshwari and S. R.K., "Bagasse Fiber Composites-A Review, "J. Mater. Environ. Sci., vol. 6, no. 3, pp. 1079-1092, 2012

[3] F. Campbell, Structural Composite materials, USA: ASM International, 2010.

[4] Behzad D. Mottahed \& Souran Manoochehri "Design consideration for electronics enclosure utylizing polymeric materials," Polymer plastic technology and engineering, pp. 883-925, 2008.

[5] C. Hoque, "Growing piles of Toxic Trash," Chemical and Engineering News, vol. 88, no. 9,p. 15, 2010.

[6] K. Leja and G. Lewandowicz, "Polymer Biodegradation and Biodegradable Polymers - A review," Polish J. of Environ. Stud., vol. 19, no. 2, pp. 255-266, 2010.

[7] J. T. Lee, M. W. Kim, Y. S. Song, T. J. Kang and J. R. Youn, "Mechanical Properties of Denim Fabric Reinforced Poly(lactic acid)," Fibers and Polymers, vol. 11, no. 1, pp. 60-66, 2010.

[8] J. Muller and A. Jimenez, "Influence of Plastizizer on thermal properties and crystallization behavior of polylactic acid films obtained by compression moulding," Polymer Science, vol. 65, pp. 970-978, 2016.

[9] K. Zhang, A. Mohanty and M. Misva, "Fully Biodegradable and Biorenewable Ternary Blends from Polylactide, Poly(3hydroxybutyrate -co- hydroxyvalerate) and Poly(butylene Succinate) with balanced properties," Applied materials and Interface, vol. 4, pp. 3091-3101, 2012.

[10] X. Zhao, Z. Ding, Q. Lin, S. Peng and P. Fang, "Toughening of Polylactide In Situ formation of Polyurethane crosslinked elastomer during reactive Blending," Applied Polymer Science, pp. 1-6, 2016.

[11] V. Jost and R. Kopitzky, "Blending of Polyhydroxybutyrate -co- valerate with Polylactic Acid for packaging applications Reflection on Miscibility and effects on the mechanical and Barrier Properties," Chem. Biochem. Eng, vol. 29, no. 2, pp. 21-246, 2015 .

[12] A. Geezy, D. Nagy and I. Hajdu, "Investigating mechanical perfomance of PLA and CA biodegradable Printed Circuit Boards," IEEE Explore, pp. 45-49, 2015.

[13] R. Schramm, A. Reinhardt and J. Franke, "Capability of Biopolymers in Electronics Manufacturing," IEEE Explore, pp. 345-349, 2012 .

[14] J. Seena, E. Deenadayalan and P. Mahanwar, "Studies on melt Processable Biocomposites of Polylactic Acid," Polyer Environment, 2014.

[15] B. Kovacs, A. Geczy, G. Horvath and I. Hadju, "Advances in Producing Functional Circits on Biodegradable PCBs," Periodica Polytechnica Electrical Engineering and Computer Science, vol. 60, no. 4, pp. 223-231, 2016.

[16] J. Thomason, "Influence of fiber length and concentration on the properties of glass fibrereinforced polypropylene: 4. Impact properties," Composites part A, vol. 28A, pp. 277-288, 1997.

Hassan K. Langat. "Investigating the Thermal and Mechanical Performance of Polylactic Acid (PLA) Reinforced with cellulose, wood fibers and Copolymer ." IOSR Journal of Polymer and Textile Engineering (IOSR-JPTE) 4.3 (2017): 25-32. 